\title{
Role of cytokines in the interplay between cancer cells and stroma-associated monocytes
}

\author{
Taoufik Nedjadi ${ }^{*}$, Eithne Costello² \\ From 2nd International Genomic Medical Conference (IGMC 2013) \\ Jeddah, Kingdom of Saudi Arabia. 24-27 November 2013
}

\section{Background}

Pancreatic cancer is characterized by the presence of a highly reactive stroma [1]. The latter harbors a variety of cellular compartments including stellate cells, fibroblasts, endothelial cells and a variety of inflammatory cells such as macrophages and monocytes. Interaction between tumour cells and surrounding stromal cells (tumour micro- environment) plays an important role in pancreatic cancer progression [2]. We have previously shown that stroma-associated monocytes express low molecular weight proteins: S100A8 and S100A9 [3]. The aim of this study is to investigate the involvement of S100A8 and S100A9 proteins in the tumour-stroma crosstalk and to decipher the potential signaling mechanism.

\section{Materials and methods}

Cell culture of pancreatic cancer cells and monocytic cells, HL-60 and primary isolated human monocytes. Isolation of Conditioned medias from pancreatic cancer cells. Western blotting analysis. Cytokines multiplexing assay (27-plex, BioRad). Cell signaling assay. Luciferase assay.

\section{Results}

1- The expression of S100A8 and S100A9 in monocytes is increased in response to soluble factors in pancreatic cancer cells conditioned media.

2- Cytokine profiling of cell supernatants, using Luminex assay, showed that PCC secrete a number of cytokines and growth factors including IL-8, FGF and TNF- $\alpha$.

3- S100A8 and S100A9 increased phosphorylation of MAPK, erk1/2 and p38 and activated NF-kB signaling pathways in a RAGE dependent manner.

\section{Conclusions}

S100A8 and S100A9 promote specific cytokine secretion from pancreatic cancer cells. Interestingly, a number of these cytokines, in turn, induce the secretion of S100A8 and S100A9 from monocytic cells, creating a paracrine loop. These events may create a favourable environment for tumour development and metastases.

\section{Authors' details}

${ }^{1}$ King Fahd Medical Centre, 21589 Jeddah, Kingdom of Saudi Arabia.

${ }^{2}$ Department of Molecular and Clinical Cancer Medicine, The University of Liverpool, Liverpool L69 3GA, UK.

Published: 2 April 2014

\section{References}

1. Hernández-Muñoz I, Skoudy A, Real FX, Navarro P: Pancreatic ductal adenocarcinoma: cellular origin, signaling pathways and stroma contribution. Pancreatology 2008, 8(4-5):462-9.

2. Erkan M, Reiser-Erkan C, Michalski CW, Kong B, Esposito I, Friess H, Kleeff J: The impact of the activated stroma on pancreatic ductal adenocarcinoma biology and therapy resistance. Curr Mol Med 2012, 12(3):288-303.

3. Sheikh AA, Vimalachandran D, Thompson CC, Jenkins RE, Nedjadi T, Shekouh A, Campbell F, Dodson A, Prime W, Crnogorac-Jurcevic T, Lemoine NR, Costello E: The expression of S100A8 in pancreatic cancerassociated monocytes is associated with the Smad4 status of pancreatic cancer cells. Proteomics 2007, 7(11):1929-40.

\section{doi:10.1186/1471-2164-15-S2-P16}

Cite this article as: Nedjadi and Costello: Role of cytokines in the interplay between cancer cells and stroma-associated monocytes. BMC Genomics 2014 15(Suppl 2):P16.

\footnotetext{
* Correspondence: tnedjadi@kau.edu.sa

${ }^{1}$ King Fahd Medical Centre, 21589 Jeddah, Kingdom of Saudi Arabia

Full list of author information is available at the end of the article
} 